\title{
Antibiotic Self-Medication and Antibiotic Resistance: Multilevel Regression Analysis of Repeat Cross-Secti- onal Survey Data in Europe
}

\author{
Alistair Anderson ${ }^{1}$ \\ ${ }^{1}$ University of Nottingham, Nottingham, United Kingdom \\ Received: 25 November 2020/Accepted: 15 November 2021
}

\begin{abstract}
Antibiotic resistance is a global public health issue with several anthropogenic drivers, including antibiotic consumption. Recent studies have highlighted that the relationship between antibiotic consumption and antibiotic resistance is contextualised by a variety of socioeconomic, cultural, and governance-related drivers of consumption behaviour and contagion that have been underexamined. A potential complication for research and policy is that measures of antibiotic consumption are often reliant on prescribing or sales data which may not easily take into account the dynamics of community consumption that include self-medication; for example, the preservation and use of leftover medication or the obtaining of antibiotics without a prescription. This study uses repeated cross-sectional survey data to fulfil two core aims: firstly, to examine the individual-level and national-contextual determinants of self-medication among antibiotic consumers in European countries, and secondly, to examine the relationship between self-medication behaviour and antibiotic resistance at the national level.

This study is particularly novel in its application of a multilevel modelling specification that includes individual-level factors with both time-variant and persistent national characteristics to examine antibiotic consumption behaviours. The key findings of the study are that survey respondents in countries with persistently higher levels of inequality, burdens of out-of-pocket health expenditure, and corruption have an increased probability of self-medicating with antibiotics. The study also highlights that overall levels of antibiotic consumption and antibiotic self-medication do not correlate and are associated heterogeneously with changes in different pathogen/antibiotic pairs. In summary, the study emphasises that antibiotic stewardship and antibiotic resistance, whilst related by biological mechanisms, are also inherently social issues. Attempts to improve antibiotic stewardship and address the challenge of antibiotic resistance should also attend to structural challenges that underlie challenges to antibiotic stewardship in the community, such as the effects of inequality and reduced access to healthcare services.
\end{abstract}

\section{Introduction}

Antibiotic resistance is a global public health problem that poses significant challenges to modern medical infrastructure. The WHO (2019) lists antimicrobial resistance as one of the top ten threats to global public health, alongside issues such as climate change and vaccine hesitancy. In the UK Government Cabinet Office (2017, p. 8) National Risk Register, antimicrobial resistance is listed alongside climate change as a long-term trend 
that is likely "to change the overall risk landscape," making current risks more severe and leading to the emergence of completely new risks.

Antibiotic resistance is the social manifestation of a biological process. The biological process at the heart of antibiotic resistance is the evolution of evasion strategies by bacteria to overcome chemical and environmental challenges, such as exposure to antibiotic medication (Wright 2007). Bacteria that survive exposure to antibiotics are then able to grow and spread due to a lack of competition from other strains. There is an inevitability to the evolutionary selection pressure that antibiotic consumption generates, meaning it is important that antibiotics are used prudently in order to mitigate the speed at which resistance develops. Understanding the relationship between unregulated offprescription antibiotic use, such as over-the-counter (OTC) sales or the use of leftover antibiotics, and levels of antibiotic resistance is consequently important for both policy and research agendas.

OTC sales of antibiotics are generally prohibited in EU Member States with the exception of some specific antibiotics in some countries; nevertheless, antibiotics are still accessible OTC or online in some Member States (Paget et al. 2017, Machowska, Lundborg 2019). There are some healthcare-system drivers associated with the ability to access antibiotics without a prescription, including a lack of enforcement of laws prohibiting OTC sales of antibiotics and requirements to dispense whole pre-packaged packages of antibiotics rather than specific quantities. Whilst the prevalence of resistance has been shown to correlate with prescribed outpatient antibiotic use, it has also been argued that the actual total consumption level includes self-medication which is not accounted for in prescription statistics and whose burden may be underestimated by sales figures (Grigoryan et al. 2006, 2010). For example, if an antibiotic course is not completed in order to keep a supply of the medication for a second course, this could lead to two sub-optimal courses. Patients' having access to antibiotics prior to visiting a healthcare professional can also drive regional variation in stewardship-related resistance drivers, as evidenced in qualitative research into clinicians' accounts of factors shaping antibiotic prescribing decisions (Brookes-Howell et al. 2012).

This study has two central aims. Firstly, to examine the determinants of selfmedication among antibiotic consumers in European countries. This aim is addressed through consideration of both individual-level characteristics and national-level contexts, with an analysis approach that accounts for both time-variant and time-invariant contexts. Secondly, to examine the relationship between self-medication behaviour and antibiotic resistance at the national level.

These aims have implications not only for policies aimed at mitigating antibiotic resistance through consumption behaviours, but also for research into this issue, since offprescription antibiotic use may not be captured by other measures, such as prescription statistics. If the level of self-medication in a country is associated with variations in antibiotic resistance measures between countries, this influence might not be captured by measures that do not account for this type of community consumption. By utilising a survey series that employs random probability sampling, this study is able to examine the association between unregulated antibiotic consumption and antibiotic resistance measures in a way that avoids the pitfalls associated with prescribing or sales data and may illuminate this methodological challenge.

\section{Literature}

\subsection{Drivers of Antibiotic Use and Self-Medication}

There are many individual-level factors associated with self-medication using antibiotics in Europe. Some of these determinants are related to individuals' feelings of illness, with multiple studies noting that self-medication is triggered in particular by upper respiratory tract symptoms, fevers, common colds, sore throats, or conditions with similar symptoms to a previous illness for which antibiotics were prescribed (Scicluna et al. 2009, Skliros et al. 2010, Shabani, Redican 2018, Druică et al. 2021). More recently, research in Australia has also found that COVID-19 pandemic-induced psychological distress has been a trigger for preventive self-medication with antibiotics (Zhang et al. 2021). 
Further drivers are associated with the combination of healthcare professionals' prescribing practices (such as providing antibiotics without a prescription, over-prescribing, and dispensing by packet rather than by number of pills), patient behaviour, and poor access to healthcare, resulting in leftover antibiotics which are then stored for later use (Eggermont et al. 2018, McNulty et al. 2006, 2007b, Grigoryan et al. 2007, Lescure et al. 2018, Guinovart et al. 2018, Machowska, Lundborg 2019). In summary, several of the factors associated with self-medication relate to the individual experience of ill health in combination with contextual and healthcare system influences.

Demographic and knowledge-related correlations with self-medication behaviours have been inconsistent across studies in Europe. McNulty et al. (2006, 2007b), for example, found in the UK that higher levels of knowledge about antibiotics were associated with both higher course completion and also the storing of antibiotics for self-medication, whilst other studies in Europe have found that lack of knowledge is associated with greater propensity for self-medication (Horvat et al. 2017, Machowska, Lundborg 2019) or had no significant bearing (Druică et al. 2021). Again, there are discrepancies in European studies regarding the association of self-medication with demographic characteristics. For example, whilst Pavydè et al. (2015) found that male, rural, and childless respondents were more likely to self-medicate in Lithuania, McNulty et al. (2006) found that younger and female respondents in the UK were more likely to hold leftover drugs. In summary, at the individual-level self-medication has a complex set of determinants, with heterogeneity among previous studies in European contexts.

More broadly, a number of socio-economic national characteristics have been associated with variations in antibiotic use, demonstrating the importance of understanding both the contextual and individual factors associated with appropriate or otherwise antibiotic use. The quality of national governance, and in particular the level of corruption, has been found to persistently associate positively with national levels of antibiotic consumption (Rönnerstrand, Lapuente 2017, Mueller, Östergren 2016, Gaygisiz et al. 2017). Additionally, national cultural dimensions have repeatedly been associated with levels of antibiotic consumption both appropriate and otherwise - especially Uncertainty Avoidance, Masculinity, and Power Distance (Gaygisiz et al. 2017, Borg 2012, Deschepper et al. 2008). Antibiotic use is more common in countries with lower tolerance for uncertainty, an emphasis on cooperation and caring for vulnerable members of society, and in countries where unequal distributions of power are less welcome. Cultural dimensions may explain why educational campaigns are not universally successful in all countries, as the messaging of responsible antibiotic use may work against rather than with the grain of national cultures established over long periods of time (Borg 2012). These same cultural dimensions also influence the healthcare workers who gatekeep access to antibiotics in most instances (Borg 2012). Intolerance for uncertainty for example, may underpin practices like more defensive medicine on the part of healthcare professionals, and unwillingness of the patient to wait out what could be a self-limiting cold and refrain from requesting antibiotics. These cultural differences, if associated causally with different patterns of antibiotic prescribing and consumption, would be indicative of the need for international policymakers to locally tailor interventions by increasing focus on, for example, on societal educational narratives or tightening regulatory mechanisms.

Variation in socio-economic and demographic factors has also been found to associate with differences in national antibiotic consumption. Countries with higher average levels of education among their populations tend to have lower levels of antibiotic consumption, and the proportions of the population above 65 years of age and below 14 years of age have both been positively associated with higher antibiotic consumption (Gaygisiz et al. 2017, Blommaert et al. 2014). The relationship between variation in national income measures and antibiotic consumption relative to other national indicators is not completely clear in high-income settings. Klein et al. (2018) argue that Gross Domestic Product (GDP) is primarily associated with antibiotic consumption in lower- and middleincome countries, and that in higher-income countries economic growth is not a factor driving variation in antibiotic consumption between countries. However, the amount spent on healthcare expressed as a percentage of GDP has been positively associated with antibiotic consumption (Blommaert et al. 2014). This suggests that in higher 
income settings such as those examined in this study, issues of culture and governance described above including resource allocation for healthcare may be more important for explaining variation in antibiotic consumption than general economic comparisons. The question of resource allocation is particularly pertinent given the context of the time period for this study, in which many countries in Europe implemented austerity measures that impacted healthcare expenditure and access (Reeves et al. 2014, Stuckler et al. 2017, ECDC 2013). Economic inequality, exacerbated by austerity measures, is also associated with the distribution of health outcomes (Mackenbach et al. 2011, EC 2013b, Chauvel, Leist 2015, Detollanaere et al. 2018) and behaviours (Kino et al. 2017) in Europe, including higher risk of infections among deprived groups and areas (ECDC 2013, Charani et al. 2021).

\subsection{Social and Economic Drivers of Antibiotic Resistance}

Antibiotic use is one among several drivers of levels of antibiotic resistance. Temporal variation in antibiotic use has been shown to correlate positively with various antibiotic resistances, such as the incidence of methicillin-resistant Staphylococcus aureus (MRSA) in hospitals and the community (Lawes et al. 2015, Aldeyab et al. 2008, Lafaurie et al. 2012, Parienti et al. 2011), with sub-national spatial variation in antibiotic prescribing also being shown to strongly positively correlate with MRSA bloodstream infections (Andreatos et al. 2018). However, there are other societal factors beyond antibiotic consumption that may compound or exacerbate the issue of antibiotic resistance by maintaining environments in which antibiotic resistance is able to develop.

Policy proposals for addressing antibiotic resistance include awareness-raising and the strengthening of antimicrobial stewardship alongside other measures such as the development of 'One Health' surveillance, improving infection prevention and control, and limiting the environmental exposure of antimicrobial resistant pathogens (Anderson et al. 2019). In previous studies, national characteristics such as levels of development, infrastructure quality, inequality, and levels of regulation have been found to explain antibiotic resistance alongside, or occasionally with better fit than, levels of antibiotic consumption (Collignon et al. 2015, 2018, Collignon, Beggs 2019, Savoldi et al. 2019, Pärnänen et al. 2019, Hay et al. 2018, Bryce et al. 2016). These social and economic conditions matter for the consideration of infection control, sanitary conditions, food handling, waste treatment, water quality, and other areas that might influence the contagion of antibiotic resistance rather than simply the development of resistance as driven by antibiotic consumption. Collignon et al. (2018) in particular argue that the use and overuse of antibiotics are drivers of the emergence and maintenance of antimicrobial resistance, whilst other social, economic, and infrastructural factors contribute with greater effect to the year-on-year changes in levels of resistance. This relationship is, however, mediated by countries' levels of economic development, for example with the volume of antibiotic use only correlating with antibiotic resistance in more economically developed regions rather than at a global scale (Collignon et al. 2018). Consequently, when considering the relationship between national-level antibiotic consumption and levels of antibiotic resistance, either cross-sectionally or longitudinally, it is necessary to also consider the factors that may aid contagion as part of the analysis in order to minimise the confounding of the consumption/resistance relationship by factors associated with greater propensity for contagion.

In summary, antibiotic consumption and antibiotic resistance are more than purely biological issues: they are deeply embedded in personal, socio-economic, and cultural contexts. Understanding variation in either specific antibiotic consumption behaviours - such as self-medication in the case of this study - or antibiotic resistance requires an appreciation of the human contexts in which these phenomena take place. By providing evidence regarding the relationship between context and behaviour, this study may inform both future research into these behaviours and future policymaking aiming to address challenges to antibiotic stewardship in European contexts. 


\section{Methods and Materials}

\subsection{Data sources}

Survey data were from the Eurobarometer survey series. Eurobarometer surveys covering European countries in 2009 (EC 2013a), 2013 (EC 2017), 2016 (EC 2019a), and 2018 (EC 2019b) posed questions about antibiotic use. Each survey sampled approximately 1,000 individuals per country (except in Cyprus, Luxembourg, and Malta, where 500 individuals are sampled per wave) using a random probability methodology and face-toface mode. The survey dataset covers 28 countries, but for the waves used in this study Croatia $(2013,2016,2018)$ was only sampled three times for the survey; Slovakia (2013, 2016, 2018) and Slovenia $(2009,2013,2016)$ only had complete antibiotic resistance data covering three years each, and Cyprus had no Hofstede Cultural Dimension data.

Country-level independent variable data were sourced from multiple locations. GDP as a time-variant measure of economic prosperity (World Bank 2020a), Out-of-Pocket health expenditure as a time-variant measure of the financial burden of healthcare for individuals (World Bank 2020b), and World Governance Indicator (World Bank 2020c) data for a time-variant measure of corruption (Control of Corruption) were sourced from World Bank datasets. Gini data as a time-variant measure of economic inequality within countries were sourced from Eurostat (2019). Hofstede's Cultural Dimensions as time-invariant measures of cultural differences between countries were sourced from Geert Hofstede (Hofstede 2015). The Hofstede Cultural Dimensions are one way of capturing cultural factors at the national level, and they position countries relative to one another along six statistically distinct dimensions of culture that describe relationships to authority, conceptions of self, and ways of dealing with dilemmas of conflict (Hofstede 2011).

Antibiotic resistance variables were selected initially based on the World Health Organisation's global priority list of antibiotic-resistant bacteria (WHO 2017) and then filtered based on the availability of data for the countries and years available in the survey data. Final bacteria-antibiotic combinations used were Escherichia coli and Klebsiella pneumoniae resistant to third-generation cephalosporins (3GCR E. coli and K. pneumoniae), MRSA, and carbapenem resistant Pseudomonas aeruginosa (CRPA). Nationallevel antibiotic resistance data were sourced from the ECDC (2020) Surveillance Atlas.

These country-level data were linked to the four-wave survey dataset by country and wave for time-variant variables, and by country for the time-invariant variable. This combined dataset included 25 sets of country-level data covering all four Eurobarometer waves and two sets of country-level data covering three waves. Cyprus was excluded from the analysis due to the lack of Hofstede Cultural Dimension data. The variables linked to the survey dataset, which were all numerically continuous, are described in Table 1. These descriptive statistics demonstrate not only that there are sizeable variations in the persistent differences between European countries for these variables, but that there are also a variety of different country-wave trajectories revealed by the ranges of the differenced variables. The construction of these differenced variables is explained in the 'Analysis' section as part of the modelling approach.

\subsection{Survey Variable Specification}

The binary dependent variable used to examine self-medication in this study covered respondents that reported having taken an antibiotic in the past 12 months, separating respondents who obtained the last course of antibiotics they used from a medical prescription or had them administered by a medical practitioner, and respondents who either used leftover antibiotics from a previous course or obtained them without a prescription. This variable was based on a question that was asked in all four Eurobarometer waves used in this study, which directed participants to reflect on their behaviour within the past year. This temporal bounding mitigates the possibility of recall issues that have been previously demonstrated with regard to antibiotic consumption questions (Anderson 2019) and improves the value of the variable as a temporal barometer for behaviour. A limitation of this variable is that it does not capture the specific antibiotic 


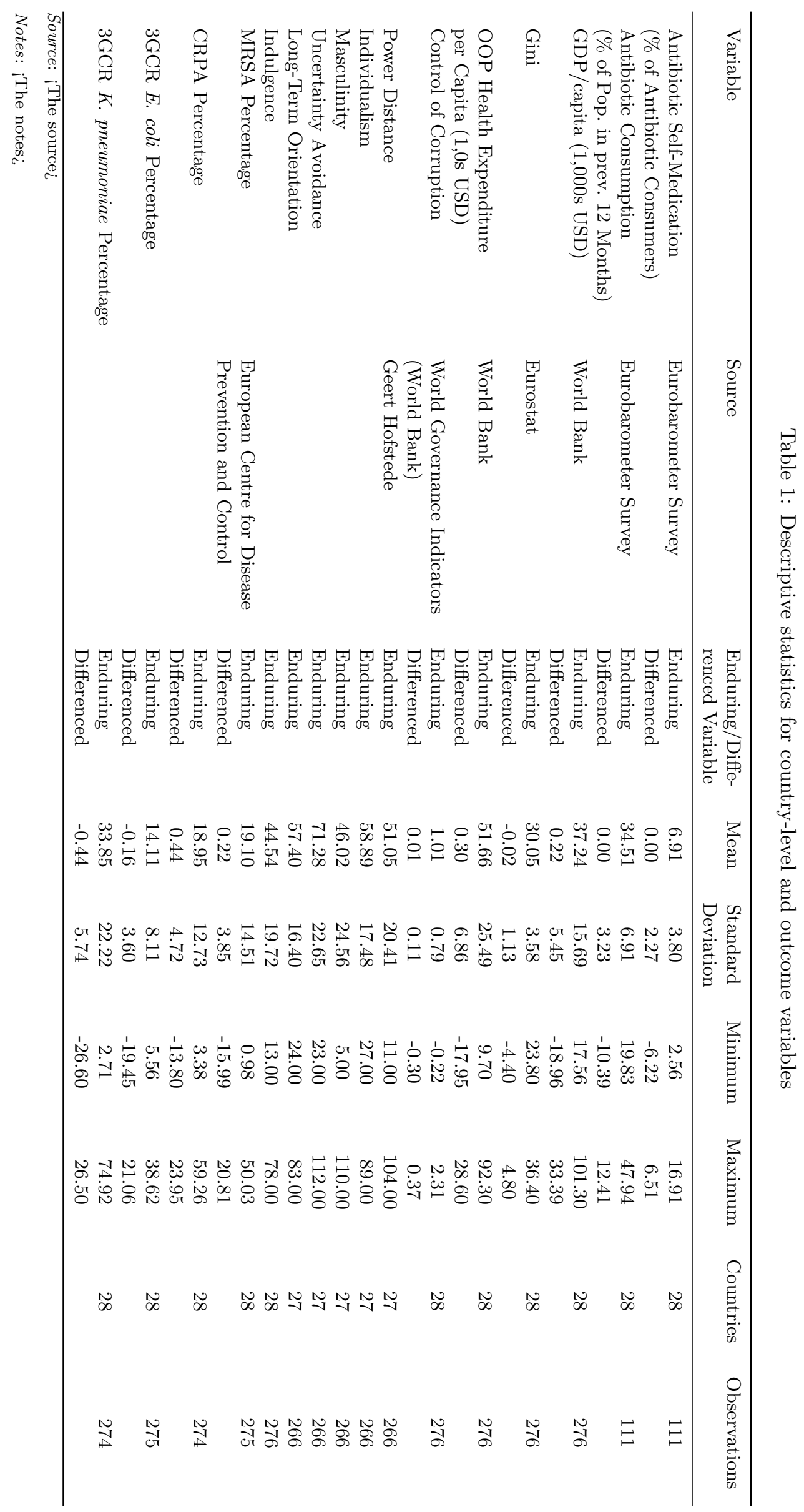




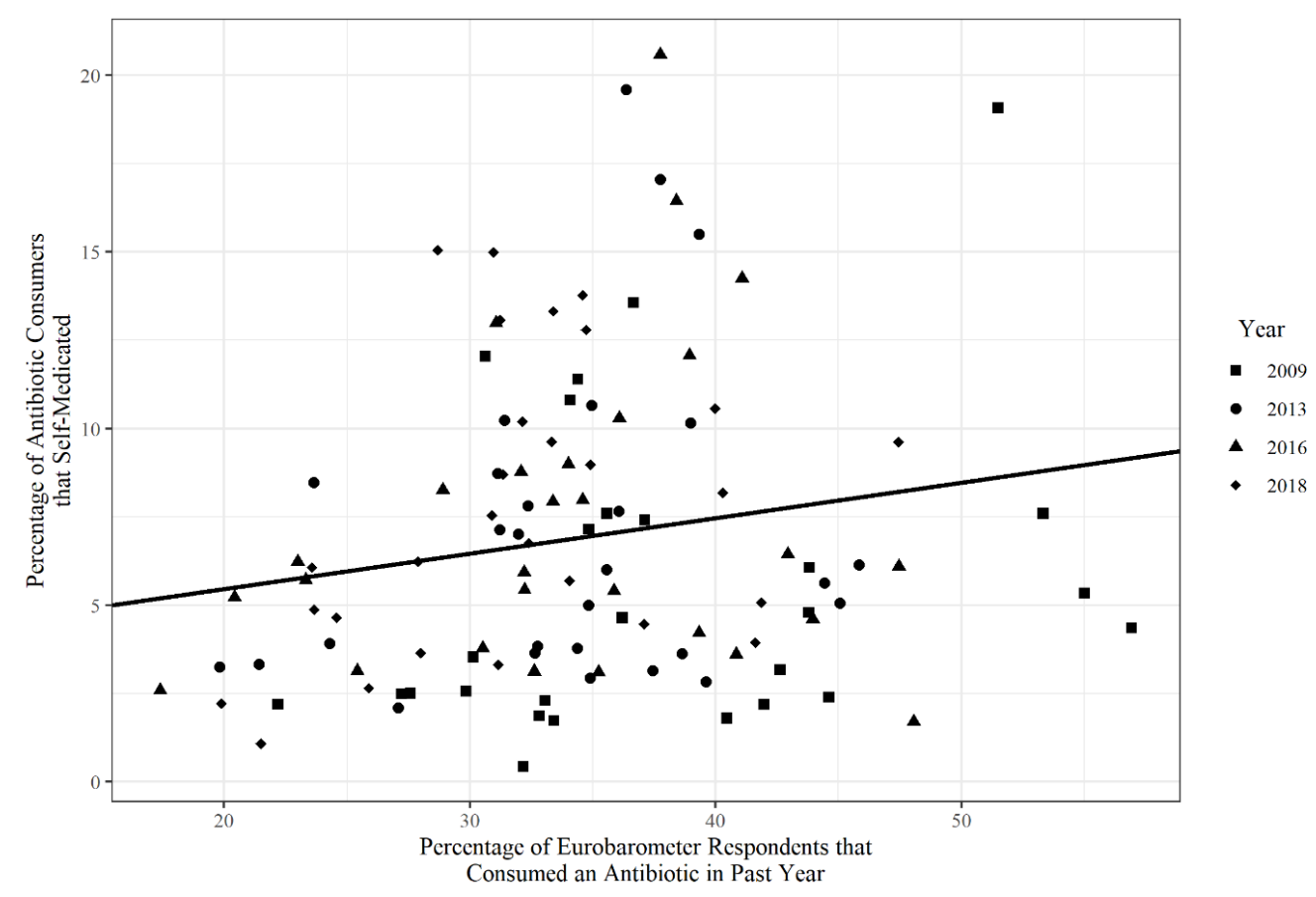

Note: $R^{2}=0.030$

Figure 1: Antibiotic consumption against the level of self-medication among antibiotic consumers for country-waves

being consumed, which does have bearing on the relationship between antibiotic consumption and resistance development (Pouwels et al. 2019). The independent antibioticrelated knowledge variables used in this study were derived from a set of four true/false questions asked in all four surveys covering whether antibiotics kill viruses (correct = false), whether antibiotics are effective against colds and flu (false), whether unnecessary use of antibiotics makes them become ineffective (true), and whether taking antibiotics often has side-effects such as diarrhoea (true). These were included as binary variables in the analyses. Overall antibiotic consumption was calculated from the Eurobarometer data to create an aggregate continuous measure for each country-wave to be controlled in the regression model.

Figure 1 shows the relationship between the outcome variable (aggregated to the country-wave level) and the aggregate overall consumption measure. A cluster-robust linear regression of self-medication against total consumption (Estimate $=0.100, p=$ 0.166, $R^{2}=0.03$ ), illustrated with a regression line in Figure 1 , confirmed that these measures were insignificantly correlated, with $3.0 \%$ of the variation in self-medication among antibiotic consumers explained by the overall level of consumption in each countrywave. This supports the rationale that self-medication may be a source of variation in actual antibiotic consumption not captured by official sources such as prescription data.

\subsection{Analysis}

The aim of the analysis was firstly to examine individual- and national-level associations with self-medication behaviour and secondly to examine whether self-medication behaviour was associated with four resistance measures from the WHO priority list.

Variable selection to control for known associations with antibiotic resistance - such as correlates relating to contagion - was informed by the literature discussed above, and bivariate cluster-robust regressions examining associations between national characteristics and nationally-aggregated self-medication behaviour. In each of these regressions, the clusters were countries, and the observations were individual years in each country.

Following these tests, a mixed-effects logistic regression model was fitted with selfmedication as the outcome variable. The model used a technique reported by Fairbrother 
(2014) (see also Schmidt-Catran, Fairbrother 2016) for the analysis of repeated crosssectional survey data, with a three-tier structure of respondents nested within countrywaves, nested within countries, to examine both time-variant and enduring national effects. By using models with random intercepts, this study is able to analyse overall associations across Europe through the regression coefficients for independent variables (fixed effects) whilst allowing the mean of the coefficients to vary across country-waves and countries. The regression model is specified by Fairbrother (2014) with $\bar{X}_{j}$ as the enduring cross-national effect, $X_{t j M}$ as the centred longitudinal component calculated by subtracting $X_{t j}$ from $\bar{X}_{j}$, and $t i m e_{t j}$ as the temporal control (in this case Year), in the following equation:

$$
y_{i t j}=\beta_{0}+\beta_{1} X_{i t j}+\beta_{2} X_{t j M}+\beta_{3} \bar{X}_{j}+\beta_{4} t i m e_{t j}+u_{j}+u_{t j}+\epsilon_{i t j}
$$

In this study, a respondent from the UK in 2009, for example, would be nested within the 2009 UK sample, which would itself be nested within the UK country level. National-level effects were separated into enduring country-level differences calculated as the median of available data for all years between 2009 and $2018\left(\bar{X}_{j}\right)$, and differenced effects within countries over time calculated as the value for a specific country-year $\left(X_{t j}\right)$ with the enduring median value for that country subtracted $\left(X_{t j M}\right)$. This approach models persistent differences between countries as well as differential trajectories in the time period, acknowledging not only that respondents within countries are more likely to be similar than between countries but that respondents sampled in the same year within a country are more likely to be similar than in different years within the same country. The exceptions to this separation were variables that were time-invariant for the study period; specifically, the Hofstede cultural dimensions.

In summary, this modelling approach provides the ability to distinguish between consistent differences between national contexts alongside differences in trajectories between countries. For example, this approach could show firstly whether countries that are persistently more economically equal are a significantly different context than those that are less equal in the context of self-medication, and also whether countries that have had large changes in inequality are a significantly different context than those that have seen little change.

Further individual-level variables were included to control for country composition, including: age interacted with gender, age respondents left education compared to the median for their country-year, presence of children in the household, local geography, and antibiotic-related knowledge. Interviewer-coded respondent cooperation was also included, as this has been found to associated with antibiotic-related outcome variables in other studies using survey data (Anderson 2020a) along with mode effects (Anderson 2020b). By controlling for individual-level variables within the analysis, including those discussed in the Literature section and these protocol variables, the effects of demographic distributions on antibiotic consumption behaviour are mitigated when analysing the higher-level associations.

Following the mixed-effects modelling, cluster-robust multiple regression was used to examine variation in country-level antibiotic resistance variables and their relationship to the aggregated survey measures of antibiotic consumption and self-medication. These models included the same socio-economic and cultural variables as the mixed-effects models, with the addition of total antibiotic consumption and percentage of antibiotic consumption that was self-medication aggregated for each wave for each country. The aims of these models were to ascertain the relationship between national measures of antibiotic resistance and, principally, the survey measure of antibiotic self-medication used as an outcome variable in the mixed-effects models.

\section{Results}

The results of this study are broken down into multiple stages to address the two key aims. The key model for the first aim (understanding the determinants of antibiotic self-medication behaviour across European countries) is a mixed-effects logistic regression model accounting for individual-level respondent characteristics discussed in 
Table 2: Results of bivariate cluster-robust linear regressions of national characteristics and the percentage of antibiotic self-medication among antibiotic consumers

\begin{tabular}{|c|c|c|c|c|}
\hline Variable & Estimate & $p$ & $R^{2}$ & $N$ \\
\hline Year & 0.233 & 0.002 & 0.03 & 111 \\
\hline Antibiotic Consumption (\% Pop. in prev. 12 months) & 0.100 & 0.166 & 0.03 & 111 \\
\hline \multicolumn{5}{|l|}{ Economic } \\
\hline GDP/capita $(1,000$ s USD $)$ & -0.087 & 0.013 & 0.12 & 111 \\
\hline Gini $(0-100)$ & 0.581 & 0.000 & 0.26 & 111 \\
\hline Out-of-Pocket Health Expenditure/capita (10s USD) & -0.040 & 0.154 & 0.06 & 111 \\
\hline \multicolumn{5}{|l|}{ Governance (-2.5-2.5) } \\
\hline Control of Corruption & -2.989 & 0.000 & 0.29 & 111 \\
\hline \multicolumn{5}{|l|}{ Cultural Dimensions (0-112) } \\
\hline Power Distance & 0.051 & 0.186 & 0.06 & 107 \\
\hline Individualism & -0.096 & 0.036 & 0.15 & 107 \\
\hline Masculinity & 0.005 & 0.822 & 0.00 & 107 \\
\hline Uncertainty Avoidance & 0.057 & 0.045 & 0.09 & 107 \\
\hline Indulgence & -0.086 & 0.005 & 0.15 & 111 \\
\hline Long-Term Orientation & 0.026 & 0.401 & 0.01 & 107 \\
\hline
\end{tabular}

the Literature section and available across all four waves of survey data, and time-variant and invariant national contextual variables. National variable selection for this mixedeffects model was informed by the Literature, along with cluster-robust linear regressions of the aggregated self-medication outcome variable against the candidate national-level variables. In particular, the cluster-robust regressions were used to determine which of the six cultural dimensions were to be included alongside the other socio-economic variables. This variable selection modelling is reported first, followed by the main model. The second aim of the study is achieved through cluster-robust regression models with national-level resistance measures as the outcomes predicted by a set of national-level characteristics.

\subsection{Bivariate Correlations: Self-Medication}

Table 2 presents the results of bivariate cluster-robust regressions of national characteristics for each country-wave on the percentage of antibiotic self-medication among antibiotic consumers. The aim of these tests was to provide initial understanding of these variables' relationships with the self-medication outcome, and to determine which cultural variables to include in the final model. National wealth represented by GDP per capita (Est $=-0.087, p=0.013, R^{2}=0.12$ ) was negatively associated with the percentage of antibiotic consumers reporting self-medication, whilst higher levels of income inequality represented through the Gini coefficient (Est $=0.581, p<0.000, R^{2}=0.26$ ) were associated positively with aggregate self-medication. There was no evidence for a significant association between out-of-pocket health expenditure (Est $=-0.040, p=0.154, R^{2}=$ $0.06)$ and the level of self-medication. Countries with greater control of corruption (Est $\left.=-2.989, p<0.000, R^{2}=0.29\right)$ were correlated with lower levels of self-medication among antibiotic consumers. Control of Corruption and the Gini coefficient had the best fit measured by $R^{2}$, accounting for $29 \%$ and $26 \%$ of the variation in aggregate self-medication in their respective bivariate models. Among the cultural dimensions, Uncertainty Avoidance (Est $=0.057, p=0.045, R^{2}=0.09$ ) was positively associated with levels of self-medication among antibiotic consumers, whilst the Individualism (Est $\left.=-0.096, p=0.036, R^{2}=0.15\right)$ and Indulgence (Est $=-0.086, p=0.005, R^{2}=0.15$ ) dimensions were negatively associated with self-medication. There was no evidence for a significant association between Power Distance (Est $=0.051, p=0.186, R^{2}=0.06$ ), Masculinity (Est $=0.005, p=0.822, R^{2}<0.01$ ), or Long-Term Orientation (Est = 
0.026, $p=0.401, R^{2}=0.01$ ) and levels of self-medication. As described with Figure 1, overall levels of antibiotic consumption in the survey samples was not correlated with levels of self-medication among antibiotic consumers. Based on these results, only the Uncertainty Avoidance, Individualism, and Indulgence cultural dimensions were included in the mixed-effects model alongside the national socio-economic variables.

\subsection{Multilevel Regression Results: Self-Medication}

Table 3 contains the results for the full mixed-effects regression model predicting whether an antibiotic consumer self-medicated or obtained antibiotics through a prescription. Compared with the reference category (15-29 year-old female), antibiotic consumers in the 30-41 $(\mathrm{OR}=1.281, \mathrm{CI}=1.059-1.549)$ year-old female respondents category were more likely to have self-medicated, whilst respondents in the $54-67(\mathrm{OR}=0.792, \mathrm{CI}=$ $0.647-0.968)$ and $67+(\mathrm{OR}=0.477, \mathrm{CI}=0.379-0.599)$ year-old female category were less likely to have self-medicated. Among males, those in the $15-29$ (OR $=1.699$, CI $=$ $1.437-2.009)$ year-old category were almost 1.7 times as likely to have self-medicated than 15-29 year-old females, whilst $30-41(\mathrm{OR}=0.684, \mathrm{CI}=0.539-0.869), 54-67$ $(\mathrm{OR}=5.593, \mathrm{CI}=0.458-0.770)$, and $67+(\mathrm{OR}=0.718, \mathrm{CI}=0.531-0.971)$ male antibiotic consumers were less likely to have self-medicated. Antibiotic consumers who had left education above the median age $(\mathrm{OR}=1.121, \mathrm{CI}=1.018-1.236)$ for their country-wave were marginally more likely to have self-medicated. Antibiotic consumers who had two or more children under the age of $10(\mathrm{OR}=0.797, \mathrm{CI}=0.672-0.946)$ were less likely to have self-medicated than antibiotic consumers without children under the age of 10, however antibiotic consumers with one child aged between 10 and 14 years $(\mathrm{OR}=1.170, \mathrm{CI}=1.023-1.338)$ were more likely to have self-medicated than consumers without children between these ages. Antibiotic consumers who correctly answered that antibiotic are not useful for treating colds and influenzas $(\mathrm{OR}=0.531$, CI $=0.47-0.588)$, that unnecessary use of antibiotics can lead to them becoming ineffective $(\mathrm{OR}=0.664, \mathrm{CI}=0.594-0.743)$, and that antibiotics cause side effects $(\mathrm{OR}=0.837$, $\mathrm{CI}=0.763-0.919)$ were all less likely to have self-medicated, though the strength of the association differed between these questions. When contrasted with 'Excellent' cooperators, antibiotic consumers who interviewers coded as having 'Bad' ( $\mathrm{OR}=1.647$, CI $=1.154-2.353)$ cooperation were more likely to have reported self-medicating behaviour.

Three national characteristics presented evidence for a significant association with propensity to self-medicate among antibiotic consumers once other factors were controlled. Antibiotic consumers in countries with persistently higher levels of income inequality (OR $=1.070, \mathrm{CI}=1.026-1.115)$ were more likely to have self-medicated than obtained their antibiotics through a prescription, however a higher rate of increase in inequality $(\mathrm{OR}=$ 0.931 , CI $=0.871-0.995)$ was associated with being less likely to have self-medicated. This clarifies the nature of the earlier finding that aggregate levels of self-medication correlated with income inequality by separating this relationship into persistent countrylevel variation and within-country temporal variation. The association of persistent differences in inequality with higher levels of self-medication was further complemented by a positive association between persistent differences in the amount of out-of-pocket health expenditure per capita $(\mathrm{OR}=1.009, \mathrm{CI}=1.000-1.018)$ and self-medication.

Additionally, respondents in countries perceived to have persistently higher levels of control over corruption $(\mathrm{OR}=0.606, \mathrm{CI}=0.413-0.888)$ were less likely to have selfmedicated in the previous 12 months. As with income inequality this finding clarifies the earlier correlation by illustrating that, for this time period, persistent differences between countries are more important for distinguishing between populations' self-medication behaviours than the rate at which change occurred within countries. There was no further evidence in the model for other national contextual associations with individuals' propensity for self-medication.

The significant results from this model are summarised in terms of their average marginal effects (AMEs) in Figure 2. In contrast to the model results, age and gender are not interacted in these AMEs. The marginal effects suggest that being a male respondent $(\mathrm{AME}=0.015, \mathrm{CI}=0.009-0.020)$ increased the chance of self-medication by $1.5 \%$, whilst being in the $42-53(\mathrm{AME}=-0.014, \mathrm{CI}=-0.024-0.004), 54-67(\mathrm{AME}=-0.031$, 
Table 3: Results for full mixed-effects logistic regression model predicting whether an antibiotic consumer self-medicated or obtained antibiotics through a prescription

\begin{tabular}{|c|c|c|c|}
\hline \multicolumn{4}{|c|}{$\begin{array}{l}\text { Self-Medication Mixed-Effects Model } \\
\text { Fixed Effects }\end{array}$} \\
\hline Variable & OR & 2.5 & 97.5 \\
\hline \multicolumn{4}{|l|}{$\begin{array}{c}\text { Individual-Level Variables } \\
\end{array}$} \\
\hline \multicolumn{4}{|l|}{ Age ${ }^{*}$ Gender (Reference: $15-29$ year old Female) } \\
\hline 30-41 Female & $1.281^{*}$ & 1.059 & $1.54 \mathrm{C}$ \\
\hline 42-53 Female & 0.902 & 0.737 & 1.105 \\
\hline 54-67 Female & $0.792^{*}$ & 0.647 & 0.968 \\
\hline $67+$ Female & $0.477^{*}$ & 0.379 & 0.599 \\
\hline 15-29 Male & $1.699^{*}$ & 1.437 & 2.009 \\
\hline 30-41 Male & $0.684^{*}$ & 0.539 & 0.86 \\
\hline 42-53 Male & 0.826 & 0.641 & 1.066 \\
\hline 54-67 Male & $0.593^{*}$ & 0.458 & 0.770 \\
\hline $67+$ Male & $0.718^{*}$ & 0.531 & 0.971 \\
\hline \multicolumn{4}{|l|}{ Age Left Education (Reference: Below Median) } \\
\hline Age Left Education (Above Median) & $1.121^{*}$ & 1.018 & 1.236 \\
\hline Still Studying & 1.025 & 0.862 & 1.220 \\
\hline \multicolumn{4}{|l|}{ Children Under 10 years old in Household (Reference: None) } \\
\hline Children Under $10(1)$ & 0.950 & 0.835 & 1.080 \\
\hline Children Under $10(2+)$ & $0.797^{*}$ & 0.672 & 0.946 \\
\hline \multicolumn{4}{|l|}{ Children 10-14 years old in Household (Reference: None) } \\
\hline Children 10-14 (1) & $1.170^{*}$ & 1.023 & 1.338 \\
\hline Children $10-14(2+)$ & 1.074 & 0.828 & 1.394 \\
\hline \multicolumn{4}{|l|}{ Local Geography (Reference: Rural) } \\
\hline Large Town & 1.053 & 0.942 & 1.178 \\
\hline Small Town & 1.059 & 0.953 & $1.17 \varepsilon$ \\
\hline \multicolumn{4}{|c|}{ Knowledge Questions (References: Incorrect or Don't Know Response) } \\
\hline Antibiotics are ineffective against viruses & 1.094 & 0.987 & 1.213 \\
\hline Antibiotics are ineffective against colds and flu & $0.531^{*}$ & 0.479 & 0.588 \\
\hline Unnecessary use of antibiotics makes them ineffective & $0.664^{*}$ & 0.594 & 0.743 \\
\hline Antibiotics cause side effects & $0.837^{*}$ & 0.763 & 0.919 \\
\hline \multicolumn{4}{|l|}{ Respondent Cooperation (Reference: Excellent Cooperation) } \\
\hline Fair Cooperation & 1.093 & 0.993 & 1.204 \\
\hline Average Cooperation & 1.099 & 0.944 & 1.280 \\
\hline Bad Cooperation & $1.647^{*}$ & 1.154 & 2.35 \\
\hline \multicolumn{4}{|c|}{ Country and Country-Wave Variables } \\
\hline Year & 1.075 & 1.034 & 1.118 \\
\hline Total Antibiotic Consumption (\% of Pop. ) (Enduring) & 0.976 & 0.952 & 1.001 \\
\hline Total Antibiotic Consumption (\% of Pop. ) (Differenced) & 1.019 & 0.993 & 1.045 \\
\hline GDP/capita (USD 1,000s) (Enduring) & 1.003 & 0.990 & 1.016 \\
\hline GDP/capita (USD 1,000s) (Differenced) & 1.001 & 0.982 & 1.021 \\
\hline Gini (Enduring) & $1.070^{*}$ & 1.026 & 1.115 \\
\hline Gini (Differenced) & $0.931^{*}$ & 0.871 & 0.995 \\
\hline OOP/capita (USD 10s) (Enduring) & $1.009^{*}$ & 1.000 & 1.018 \\
\hline OOP/capita (USD 10s) (Differenced) & 0.995 & 0.983 & 1.007 \\
\hline Control of Corruption (Enduring) & $0.606^{*}$ & 0.413 & 0.888 \\
\hline Control of Corruption (Differenced) & 0.814 & 0.429 & 1.547 \\
\hline Individualism & 0.993 & 0.984 & 1.003 \\
\hline Uncertainty Avoidance & 0.993 & 0.986 & 1.001 \\
\hline Indulgence & 0.997 & 0.985 & 1.00 \\
\hline \multicolumn{4}{|l|}{ Random Effects } \\
\hline & Standard & & \\
\hline & Deviation & & \\
\hline & (Intercepts) & & \\
\hline Country-Year (107 levels) & 0.263 & & \\
\hline Country (27 levels) & 0.252 & & \\
\hline
\end{tabular}




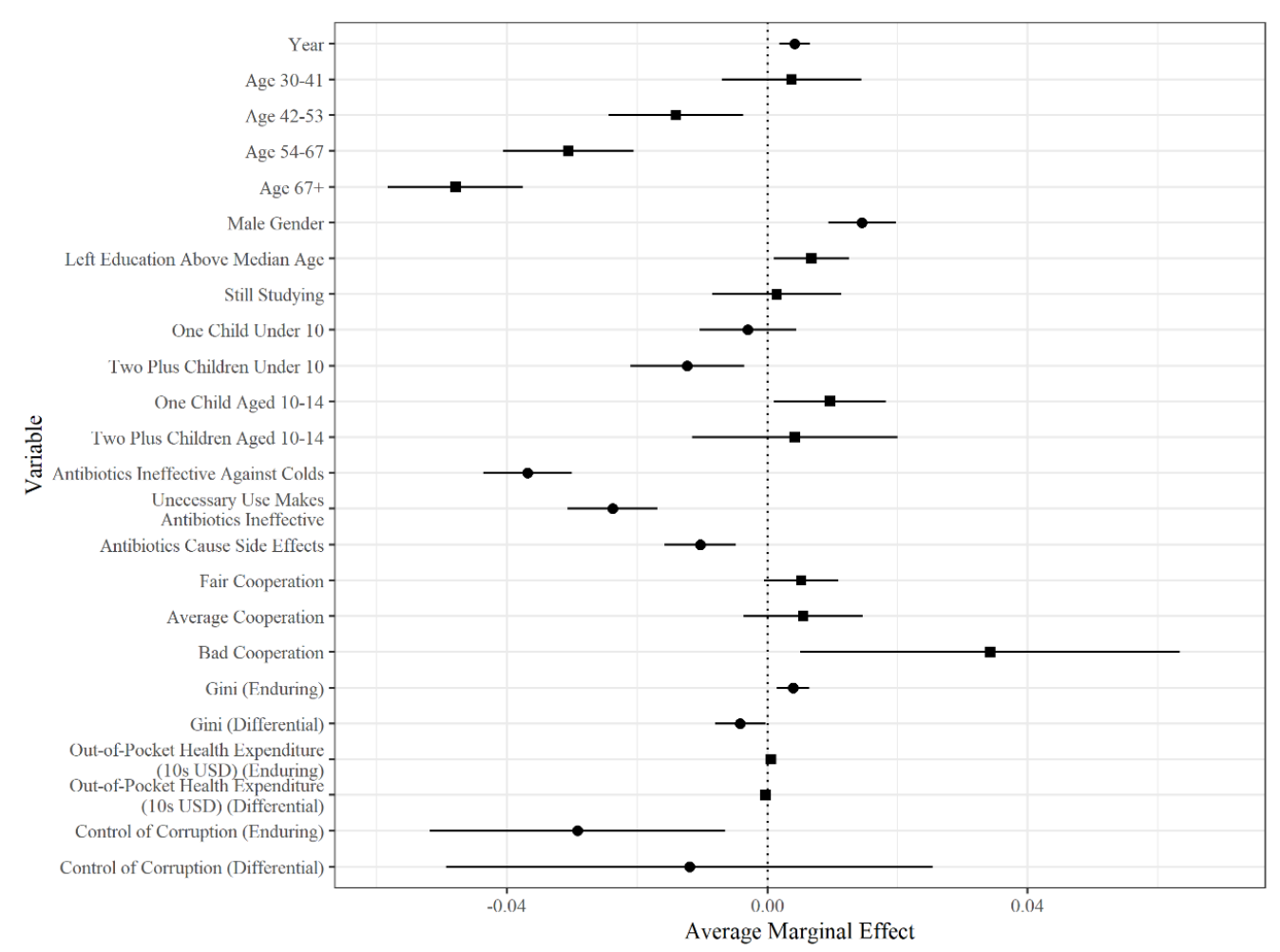

Figure 2: Average marginal effects of significant variables in the mixed-effects regression model, with $95 \%$ confidence intervals

$\mathrm{CI}=-0.041-0.021)$, and $67+(\mathrm{AME}=-0.048, \mathrm{CI}=-0.0583-0.0376)$ age categories decreased the change of self-medication by $1.4 \%, 3.1 \%$, and $4.8 \%$ respectively. However, as the model output in Table 3 highlights, the age quintiles do interact with gender categories to produce more nuanced trajectories across the age groups, albeit with similar interpretations. The marginal effects were generally comparable in size, for example with overlapping confidence intervals for each of having two or more children under ten years of age $(\mathrm{AME}=-0.012, \mathrm{CI}=-0.021-0.004)$ reducing the change of self-medication by $1.2 \%$, responding correctly regarding antibiotics being ineffective for treating colds and flu $(\mathrm{AME}=-0.037, \mathrm{CI}=-0.044-0.030)$ reducing the chance by $3.7 \%$, unnecessary usage of antibiotics rendering them ineffective (AME $=-0.024, \mathrm{CI}=-0.031-0.017$ ) reducing the change by $2.4 \%$, and antibiotics causing side effects $(\mathrm{AME}=-0.010, \mathrm{CI}=-0.016$ -0.005 ) reducing the change by $1 \%$. Similarly, among positive associations there were comparable magnitudes of AME for changes in year $(\mathrm{AME}=0.004, \mathrm{CI}=0.002-0.007$ ) with the chance of a self-medication response increasing by $0.4 \%$ per year, and having left education above the median age for the country-wave $(\mathrm{AME}=0.007, \mathrm{CI}=0.001-$ 0.011 ) increasing the chance of a self-medication response by $0.7 \%$, and having one child aged 10-14 $(\mathrm{AME}=0.010, \mathrm{CI}=0.001-0.018)$ increasing the chance of self-medication by $1 \%$. Respondents categorised as bad co-operators $(\mathrm{AME}=0.034, \mathrm{CI}=0.005-0.063)$ were $3.4 \%$ more likely to have provided a self-medication response.

At the country level, the AMEs represent continuous rather than discrete variables. For each increased point on the Gini coefficient representing a persistent difference between countries $(\mathrm{AME}=0.004, \mathrm{CI}=0.001-0.006)$ the likelihood of a self-medication response increased by $0.4 \%$, whilst for each point above the median Gini for the country in the time period $(\mathrm{AME}=-0.004, \mathrm{CI}=-0.008-0.000)$ the likelihood of self-medication decreased by $0.4 \%$. For each persistent 10USD increase in out-of-pocket health expenditure per capita $(\mathrm{AME}=0.001, \mathrm{CI}=0.000-0.001)$ the likelihood of self-medication increased by $0.1 \%$, and for each increased point measuring Control of Corruption as a persistent difference between countries ( $\mathrm{AME}=-0.029$, CI $=-0.052-0.006$ ) the likelihood of self-medication decreased by $2.9 \%$. The contrasting trajectories of the 

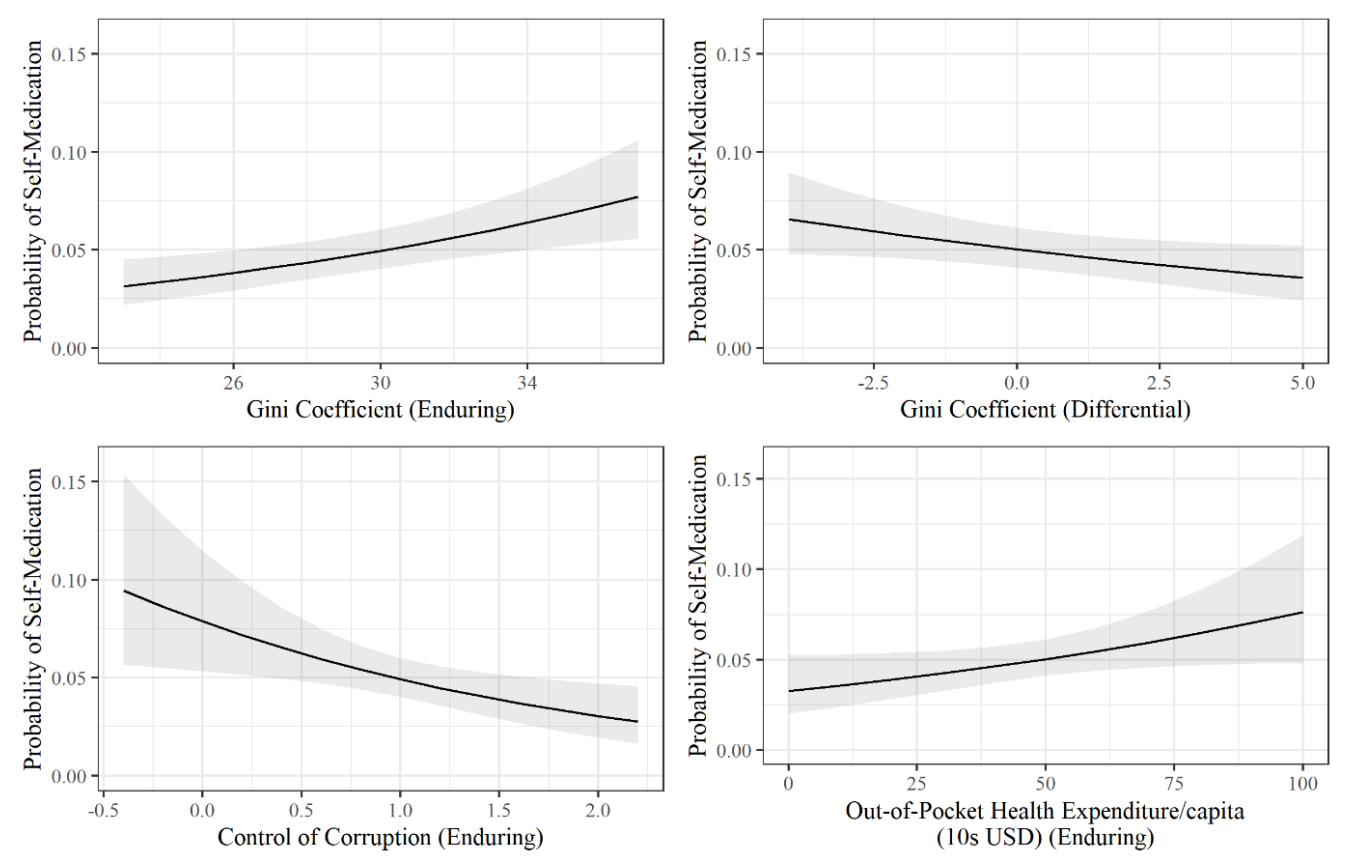

Figure 3: Predicted probabilities of self-medication for individuals in countries with persisting differences in inequality, corruption, and out-of-pocket health expenditure with $95 \%$ confidence intervals

predicted probabilities for these significant contextual variables are illustrated in Figure 3.

\subsection{Cluster-Robust Linear Regressions: Antibiotic Resistance}

Table 4 presents the results of cluster-robust multiple regressions of national characteristics on national-level antibiotic resistance measures for the selected antibiotic/pathogen combinations. There were multiple patterns of association across the four measures, evidencing a lack of homogeneity between the distributions of the antibiotic/pathogen combinations. Overall antibiotic consumption was only associated with the MRSA (Est $=0.633, p=0.001$ ) and 3GCR $K$. pneumoniae (Est $=-0.670, p=0.005$ ) resistance measures, being associated positively with MRSA and negatively with $3 \mathrm{GCR} \mathrm{K}$. pneumoniae. It is worth noting that in a bivariate regression, 3GCR $K$. pneumoniae was positively and insignificantly associated (Est $=0.751, p=0.08$ ) with antibiotic consumption and the association only became negative and significant after the introduction of Control of Corruption, suggesting an element of confounding between consumption, 3GCR K. pneumoniae, and corruption measured at the national level. The proportion of self-medication within overall antibiotic consumption however was positively associated with CPRA (Est $=0.907, p=0.013$ ) only.

National wealth, represented as GDP/capita, was positively associated (Est $=0.398$, $p=0.001$ ) with the level of $3 \mathrm{GCR} K$. pneumoniae at the national level, and the level of out-of-pocket health expenditure per capita was positively associated with 3GCR $E$. coli $($ Est $=0.084, p=0.023)$. Control of Corruption was a significant variable for multiple resistance measures, with negative associations for CPRA (Est $=-11.069, p$ $=0.004)$, 3GCR E. coli $($ Est $=-8.516, p<0.000)$, and 3GCR K. pneumoniae (Est $=$ $-28.217, p<0.000)$. This means that countries perceived to have a better handle on corruption tended to have lower levels of these resistance pairings, with the association most pronounced in relation to $3 \mathrm{GCR} K$. pneumoniae. In countries that were more Indulgent there tended to be a higher level of MRSA (Est $=0.290, p=0.026$ ), whilst in countries that were more prone to avoiding uncertainty there were lower levels of $3 \mathrm{GCR}$ E. $\operatorname{coli}($ Est $=-0.110, p=0.034)$. 


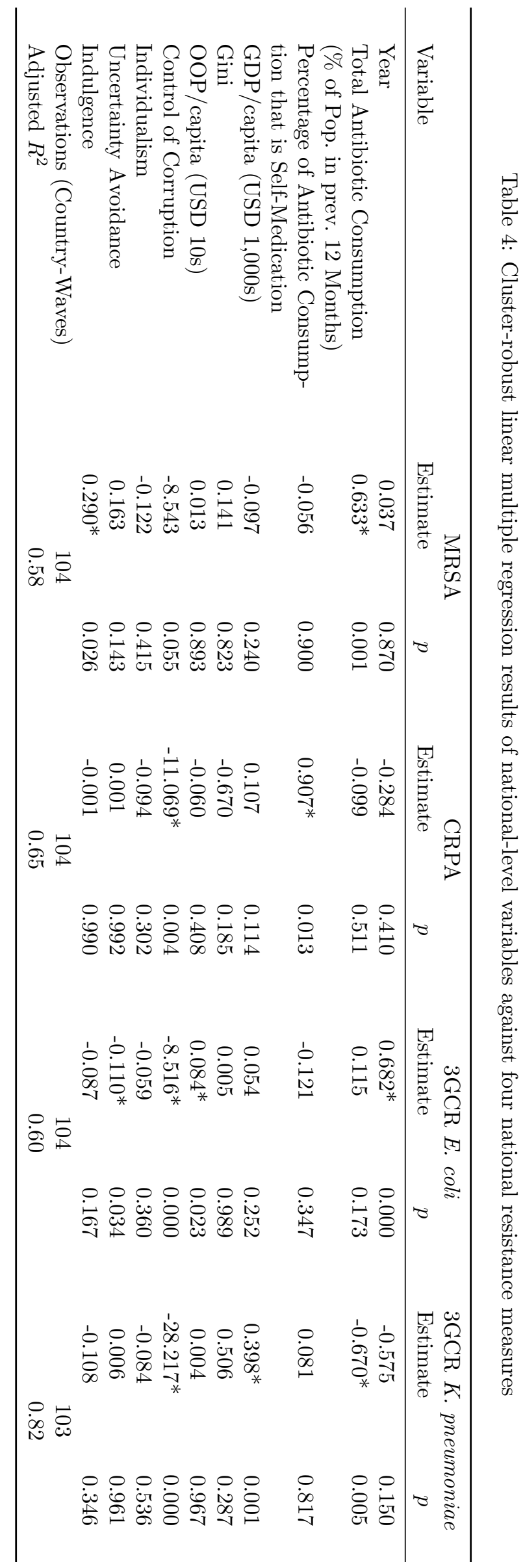




\section{Discussion}

Antibiotic consumption is one among a number of drivers of antibiotic resistance, and the extent to which national variation in levels of antibiotic consumption are associated with variation in levels of antibiotic resistance relative to other drivers (such as contagion-related factors) has been the subject of recent research. Antibiotic use measured through prescriptions or sales may not adequately capture consumption via self-medication however, defined in this study as the practice of using leftover antibiotics from previous prescriptions or otherwise obtaining antibiotics without a prescription. Self-medication varies between countries and does not directly correlate with overall antibiotic consumption, as demonstrated through the measures derived and correlated in this study using random-probability survey samples of self-reported behaviour. The explicit examination of associations between individual-level characteristics and macrolevel contexts and self-medication among antibiotic consumers is thus the first key contribution of this study, followed by the examination of how total consumption and levels of self-medication correlate with national measures of four different antibiotic/bacteria combinations from the WHO priority list.

\subsection{Self-Medication in Europe: Individual-Level Characteristics}

Compliance with instructions for medication-taking is associated with several identified factors, including age, patient-physician relationship, beliefs about medications, misconceptions about disease conditions, experience and management of side-effects, and individual personality traits (Foot et al. 2016, Aslani, Schneider 2014, Axelsson 2013). The findings of this study support those of previous studies focusing on public antibiotic stewardship behaviours. The finding that higher levels of education are associated with a higher propensity for self-medicating behaviour among antibiotic consumers supports previous research that has demonstrated associations between higher levels of education and inappropriate stewardship behaviour (McNulty et al. 2007a, Shehadeh et al. 2012). The finding that among antibiotic consumers, younger age groups of both male and female genders have a higher propensity to self-medicate also supports previous studies that have found that younger age groups are more likely to report inappropriate attitudes and behaviours regarding antibiotic use (Anderson 2020a, Pechère et al. 2007, Napolitano et al. 2013, Kardas et al. 2007).

This study suggests that specific aspects of knowledge about antibiotics and antibiotic resistance are relevant to self-medication propensity within European countries. The raising of public awareness through education has been a key area of policy action addressing antibiotic resistance, aiming to inform the public about how to take antibiotics appropriately and the consequences of inappropriate antibiotic use through credible professional sources (McParland et al. 2018, Price et al. 2018). Public health interventions commonly include knowledge-based components (McParland et al. 2018, Price et al. 2018), though the relationship between individuals' knowledge and their behaviour with antibiotics has a mixed evidence base. Knowledge about antibiotics and antibiotic resistance has been associated in the literature with good stewardship attitudes and behaviours (Anderson 2018, Kim et al. 2011, Jamhour et al. 2017, Horvat et al. 2017, Vallin et al. 2016, Chan et al. 2012, McNulty et al. 2007b), as well as with negative behaviours such as self-medication or retaining leftovers (McNulty et al. 2007b, Pan et al. 2012). In addition to knowledge about antibiotics as a medication, meta-analyses of adherence to medication have shown that individuals believing that the medication is necessary for their health are more likely to follow medication-taking instructions, while individuals that have strong concerns about the medication, such as beliefs about sideeffects, are less likely to follow instructions (Foot et al. 2016, Aslani, Schneider 2014, Axelsson 2013, Horne et al. 2013).

This study contributes to these previous studies, having examined the relationship between multiple aspects of individual-level knowledge about antibiotics. Specifically, and with the strength of a large multi-country and multi-year survey dataset, this study provides evidence that three specific aspects of knowledge about antibiotics and antibiotic resistance are salient with regard to self-medication behaviour in Europe. Respondents 
that correctly responded that antibiotics cannot treat colds, that unnecessary use of antibiotics exacerbates antibiotic resistance, and that antibiotic consumption commonly comes with side-effects, were all less likely to have provided a self-medication response. This might suggest that practical messaging linked to specific illness conditions may be more effective for curbing self-medication behaviour than what may be more abstract messages about not treating viral illness with antibiotics, for which comprehension involves some academic understanding of biology. The association between knowledge of the link between unnecessary antibiotic use and the development of antibiotic resistance and lower propensity for self-medication was a positive sign that behaviour may be associated with understanding of public health consequences. Similarly, the association between knowing about antibiotics' side-effects and lower propensity for self-medication is also positive and may suggest that this knowledge makes antibiotics a less attractive option for consumers that have not sought medical advice and may be in doubt over whether antibiotics are necessary or not. However, this discussion must be caveated by the cross-sectional nature of the data that gives these causal attributions a speculative nature, since any causal association could go both ways between the outcome (selfmedication) and predictors (knowledge). For example, obtaining antibiotics via prescription necessarily entails a visit to and interaction with a health professional who may provide educational information, and this could also be a principal explanation for the positive associations discussed above.

\subsection{Self-Medication in Europe: Inequality and Corruption}

This study suggests that there are some contextual factors relevant to self-medication behaviour in Europe in addition to the above compositional factors. Inequality, as measured by the Gini coefficient, has been found to be an illustrative measure of inequality in the distribution of health outcomes (Mackenbach et al. 2011, EC 2013b, Chauvel, Leist 2015, Detollanaere et al. 2018) and modifiable health behaviours (Kino et al. 2017) in Europe. This study suggests that antibiotic self-medication is part of the mosaic of poor health outcomes and modifiable behaviours differentiating the health of countries with persistently higher income inequality from those with lower inequality.

Increased income inequality is associated with greater precarity for individuals at the low end of the income spectrum, referred to as, for example, the 'precariat' (Standing 2014, Greenstein 2020). In this study, persistent differences in income inequality between European countries from 2009 to 2018 were associated with variation in levels of self-medication behaviour, with people in countries experiencing persistently higher levels of income inequality over this time period more likely to be associated with selfmedication behaviour. Alongside this, countries in which people bore persistently higher burdens of out-of-pocket health expenditure also saw higher levels of self-medication behaviour with antibiotics. During this time period, several countries implemented austerity measures in response to the $2007 / 8$ financial crisis that negatively impacted upon funding, access to, and the provision of healthcare (Reeves et al. 2014, Stuckler et al. 2017, ECDC 2013). Sargent, Kotobi (2017), for example, highlight that some areas in France experienced "medical desertification" that was particularly damaging to marginalized groups. There may consequently be several non-exclusive explanations for why countries experiencing higher levels of inequality may also experience higher levels of antibiotic self-medication among their population. Charani et al. (2021, p. 2), for example, highlight that "low vaccination coverage persists in marginalized communities in many settings" and that, "socioeconomic deprivation is a risk factor for many infectious diseases including TB and meningococcal disease." Economic precarity could be associated with an inability to afford time away from work for illness, an inability to pay for medication, and higher levels of ill health prompting antibiotic consumption, whilst austerity measures that significantly affect vulnerable and deprived groups may reduce access to healthcare services and be generative of leftover-retaining behaviours. What remains unexplained, however, is why years with above average inequality over the 2009-2018 period tended to see lower levels of self-medication behaviour, or, to reverse the trend: why years with below-average inequality tended to see higher levels of selfmedication behaviour. This area warrants further research using qualitative approaches 
that can provide more in-depth explanations of the relationship between economic precarity and antibiotic self-medication in Europe. Whilst a definitive explanation cannot be provided by this study, the results are suggestive that interventions to address antibiotic self-medication in Europe should also aim to address structural economic factors that may underly individuals' self-medication behaviour.

This study also suggest that countries with greater control of corruption have lower levels of self-medication among antibiotic consumers, which supports previous suggestions that poorly controlled corruption is associated with a higher level of undocumented antibiotic use (Collignon, Beggs 2019) in addition to general antibiotic use (Rönnerstrand, Lapuente 2017, Mueller, Östergren 2016, Gaygisiz et al. 2017). As Collignon, Beggs (2019, p. 6) articulate: "If corruption is poorly controlled, it is much more likely that there will be antibiotic use that is undocumented and so antibiotic volumes used, and their effects, will not be reflected in official figures." This study directly supports this suggestion by evidencing that countries with persistently higher levels of (perceived) corruption are associated with greater propensity for self-medication - an undocumented form of antibiotic consumption - among antibiotic consumers.

\subsection{Social Correlates of Antibiotic Resistance}

The findings of this study regarding the relationship between antibiotic consumption, self-medication, and national resistance levels suggest that there are different impacts across pathogen/antibiotic combinations for different aggregated levels of antibioticrelated behaviour. A strong association has been shown between the use of carbapenems to treat P. aeuruginosa infections and the development of resistance (Carmeli et al. 1999, Lepper et al. 2002, Rossolini, Mantengoli 2005, Mladenovic-Antic et al. 2016), and in particular the use of sub-inhibitory concentrations of antibiotics (Wright et al. 2013). The finding in this study that high self-medication countries also tended to have higher levels of CRPA suggests that the maintenance of CRPA levels is in part attributable to poorly enforced regulation of antibiotic consumption, as members of the public are more likely to have obtained the antibiotics they consumed in the past year off-prescription. This is further supported by the negative association presented between the perception of how well corruption is controlled in each country and the level of CRPA. These are only correlations of aggregated data about antibiotic use broadly defined however, and do not reveal the impact of specific classes of antibiotic. Indeed, the cross-sectional nature of the data could also mean that any causal pathway operates in the reverse direction to that suggested above, with higher levels of CRPA leading to higher demand for off-prescription antibiotics.

Previous research has demonstrated relationships between antibiotic stewardship interventions and the development of MRSA (Aldeyab et al. 2008, Lafaurie et al. 2012, Lawes et al. 2015), as well as regionally aggregated antibiotic consumption and MRSA bloodstream infection rates (Andreatos et al. 2018). This study provides support for these previous studies by presenting a positive association between nationally aggregated levels of antibiotic consumption and nationally-aggregated levels of MRSA. Previous studies also demonstrate a positive association between antibiotic consumption, particularly third-generation cephalosporins, and resistant K. pneumoniae (Joseph et al. 2015, Lombardi et al. 2015, Yang et al. 2020). The present study would seem to contradict this previous research by suggesting that there is a negative relationship between national antibiotic consumption levels and the level of 3GCR K. pneumoniae. However, this result is not necessarily anomalous, as a previous study by (Carlet et al. 2020) showed that in France contrasting results were found regarding the relationship between antibiotic consumption (which was reduced following a public campaign) and some antibiotic resistance pairs. Carlet et al. (2020) showed that whilst resistance levels decreased among $S$. aureus, the resistance of $K$. pneumoniae to third-generation cephalosporins increased. This study echoes this with a positive association between overall consumption and levels of MRSA and a negative association between overall consumption and 3GCR K. pneumoniae in the time period. Again, a clear caveat to this is that the surveybased antibiotic consumption measures in this study do not account for the consumption of specific classes of antibiotic or changing patterns of prescribing that might lead to 
higher or lower use of third-generation cephalosporins in different countries. However, along with the association between levels of self-medication and CRPA, and the lack of evidence for an association between antibiotic consumption (prescribed or otherwise) and levels of 3GCR E. coli levels, these results do illustrate heterogeneity between pathogen/antibiotic pairs in terms of their relationship to controlled or otherwise antibiotic consumption broadly measured.

Importantly, this study included a number of socio-economic and cultural factors to further contextualise the relationships between antibiotic consumption, self-medication, and resistance measures. As with the antibiotic consumption measures, this study illustrates that there are varied factors associated with different resistance measures. Indeed, 3GCR E. coli levels were predominantly characterised in terms of socio-economic and cultural factors, including out-of-pocket health expenditure per capita, corruption, and cultural avoidance of uncertainty, rather than the level of consumption of antibiotics. Corruption was a significant factor associated with levels of antibiotic resistance, more so than either of the measures of antibiotic consumption used, supporting the argument that poor governance (and in particular, high levels of corruption) is a significant barrier to addressing antibiotic resistance (Collignon et al. 2015, 2018, Collignon, Beggs 2019). Together these demonstrate that, socially, the challenge of 'antibiotic resistance' is a broad church, and that addressing resistance between specific pathogens and classes of antibiotic requires attention to the varied societal contexts that may aid the development of various pathogenic ecologies, as well as the improvement of antibiotic stewardship.

\subsection{Limitations}

This study has multiple limitations that should be acknowledged. Whilst the modelling approach distinguished between persistent and time-variant country-level differences, the data used are cross-sectional in nature. This limits the potential for causal pathways to be determined, and whilst these have been suggested in the context of existing literature, alternative and potentially opposing pathways cannot be definitively ruled out. Survey data themselves contain inherent limitations as a trade-off against large-scale data collection and analysis. Specifically for this study, whilst associations with 'antibiotic consumption' and 'self-medication' can be determined, the motivations of individuals and the specific experiences that underly these behaviours cannot be analysed in detail. For example, the relationship between inequality and self-medication was explained with a contextual rationale in this paper, but this area requires in-depth qualitative research to fully understand the conditions that precipitate higher levels of self-medication in the countries that have higher inequality. Furthermore, the survey-based measures of antibiotic consumption used in this study do not discriminate between prescribing policies concerning the use of specific classes of antibiotics, which may influence patterns of resistance between countries.

\section{Conclusion}

This study makes two key contributions to the literature. Firstly, it demonstrates that antibiotic consumers in European countries with persistently higher levels of income inequality, burdens of out-of-pocket health expenditure, and corruption are more likely to consume antibiotics without a prescription than consumers in countries with lower levels of inequality, out-of-pocket health expenditure, and corruption. This finding is important, as measures of national antibiotic consumption between countries that do not take into account off-prescription consumption may produce unreliable results confounded by the level of inequality or out-of-pocket health expenditure or extent of corruption in different countries. This study was able to distinguish, albeit broadly, between antibiotic consumption and self-medication by using survey-based measures rather than prescribing or sales data, and was able to distinguish between persistent and time-variant differences between countries using a mixed-effects regression technique. Secondly, the study has demonstrated that, whilst relationships between different pathogen/antibiotic pairs and antibiotic consumption, self-medication, and socio-economic and cultural factors are heterogeneous, socio-economic and cultural factors play an 
important role in explaining national variations in resistance. Whilst levels of corruption appear to correlate with both self-medication and resistance levels, other factors like cultural dimensions and economic variables presented different patterns across different resistance pairs. Approaches to improve antibiotic stewardship in Europe by addressing self-medication behaviours should take into account the structural factors that underlie such behaviours, in addition to individual-level approaches like educational interventions. Furthermore, these approaches should take into account that antibiotic resistance is not simply driven by antibiotic consumption, but is contextualised by social, economic, and cultural environments.

\section{References}

Aldeyab MA, Monnet DL, López-Lozano JM, Hughes CM, Scott MG, Kearney MP, Magee FA, Mcelnay JC (2008) Modelling the impact of antibiotic use and infection control practices on the incidence of hospital-acquired methicillinresistant Staphylococcus aureus: A time-series analysis. Journal of Antimicrobial Chemotherapy 62: 593-600. CrossRef.

Anderson A (2018) Online health information and public knowledge, attitudes, and behaviours regarding antibiotics in the UK: Multiple regression analysis of Wellco me Monitor and Eurobarometer data. PLoS ONE 13: e0204878. CrossRef.

Anderson A (2019) "We tried to, but life gets in the way": The value of cognitive interviewing for testing a questionnaire on antibiotic consumption behaviours. Unrefereed preprint. available at: https://osf.io/preprints/socarxiv/zyq2t. CrossRef.

Anderson A (2020a) Analysing incompliant attitudes towards antibiotic prescription completion in the UK. Journal of Antimicrobial Chemotherapy 75: 756-763. CrossRef.

Anderson A (2020b) Knowledge about antibiotics and attitudes towards vaccination: Regression analysis of wellcome monitor survey data. Unrefereed preprint. available at: https://osf.io/preprints/socarxiv/bnadr/. CrossRef.

Anderson M, Clift C, Schulze K, Sagan A, Nahrgang S, Ouakrim DA, Mossialos E (2019) Averting the AMR crisis: What are the avenues for policy action for countries in Europe? Available at: https://www.euro.who.int/__data/assets/pdf_file/0005/397652/PolicyBrief_PB32_FINAL_WEB.pdf

Andreatos N, Shehadeh F, Pliakos EE, Mylonakis E (2018) The impact of antibiotic prescription rates on the incidence of MRSA bloodstream infections: A country-level, USwide analysis. International Journal of Antimicrobial Agents 52: 195-200. CrossRef.

Aslani P, Schneider MP (2014) Adherence: The journey of medication taking, are we there yet? International Journal of Clinical Pharmacy 36: 1-3. CrossRef.

Axelsson M (2013) Report on personality and adherence to antibiotic therapy: A population-based study. BMC Psychology 1: 24. CrossRef.

Blommaert A, Marais C, Hens N, Coenen S, Muller A, Goossens H, Beutels P (2014) Determinants of between-country differences in ambulatory antibiotic use and antibiotic resistance in Europe: A longitudinal observational study. Journal of Antimicrobial Chemotherapy 69: 535-547. CrossRef.

Borg MA (2012) National cultural dimension as drivers of inappropriate ambulatory care consumption of antibiotics in Europe and their relevance to awareness campaigns. Journal of Antimicrobial Chemotherapy 67: 763-767. CrossRef.

Brookes-Howell L, Hood K, Cooper L, Little P, Verheij T, Coenen S, Godycki-Cwirko M, Melbye H, Borras-Santos A, Worby P, Jakobsen K, Goossens H, Butler CC (2012) Understanding variation in primary medical care: A nine-country qualitative study of clinicians' accounts of the non-clinical factors that shape antibiotic prescribing decisions for lower respiratory tract infection. BMJ Open 2: e000796. CrossRef. 
Bryce A, Hay AD, Lane IF, Thornton HV, Wootton M, Costelloe C (2016) Global prevalence of antibiotic resistance in paediatric urinary tract infections caused by Escherichia coli and association with routine use of antibiotics in primary care: Systematic review and meta-analysis. BMJ 352: i939. CrossRef.

Carlet J, Jarlier V, Acar J, Debaere O, Dehaumont P, Grandbastien B, Coz PL, Line G, Pean Y, Rambaud C, Roblot F, Salomon J, Schlemmer B, Tattevin P, Vallet B (2020) Trends in antibiotic consumption and resistance in france over 20 years: Large and continuous efforts but contrasting results. Open Forum Infectious Diseases 7 : ofaa452. CrossRef.

Carmeli Y, Troillet N, Eliopoulos G, Samore M, H. M (1999) Emergence of antibioticresistant Pseudomonas aeruginosa: Comparison of risks associated with different antipseudomonal agents. Antimicrobial Agents and Chemotherapy 43: 1379-1382

Chan YH, Fan MM, Fok CM, Lok ZL, Ni M, Sin CF, Wong KK, Wong SM, Yeung R, Yeung TT, Chow WC, Lam TH, Schooling CM (2012) Antibiotics nonadherence and knowledge in a community with the world's leading prevalence of antibiotics resistance: Implications for public health intervention. American Journal of Infection Control 40: 113-117. CrossRef.

Charani E, Mendelson M, Ashiru-oredope D, Hutchinson E, Kaur M, Mckee M, Mpundu M, Price JR, Shafiq N, Holmes A (2021) Navigating sociocultural disparities in relation to infection and antibiotic resistance - the need for an intersectional approach. JACAntimicrobial Resistance 3. CrossRef.

Chauvel L, Leist AK (2015) Socioeconomic hierarchy and health gradient in Europe: The role of income inequality and social origins. International Journal for Equity in Health 14: 132. CrossRef.

Collignon P, Athukorala PC, Senanayake S, Khan F (2015) Antimicrobial resistance: The major contribution of poor governance and corruption to this growing problem. PLoS ONE 10: e0116746. CrossRef.

Collignon P, Beggs JJ (2019) Socioeconomic enablers for contagion: Factors impelling the antimicrobial resistance epidemic. Antibiotics 8: 86. CrossRef.

Collignon P, Beggs JJ, Walsh TR, Ganrda S, Laximinarayan R (2018) Anthropological and socioeconomic factors contributing to global antimicrobial resistance: A univariate and multivariable analysis. Lancet Planetary Health, 2, e398-405. CrossRef.

Deschepper R, Grigoryan L, Lundborg CS, Hofstede G, Cohen J, Kelen GVD, Deliens L, Haaijer-ruskamp FM (2008) Are cultural dimensions relevant for explaining crossnational differences in antibiotic use in Europe? BMC Health Services Research 8: 123. CrossRef.

Detollanaere J, Desmarest AS, Boeckxstaens P, Willems S (2018) The link between income inequality and health in Europe, adding strength dimensions of primary care to the equation. Social Science \& Medicine 201: 103-110. CrossRef.

Druică E, Băicuş C, Ianole-călin R, Fischer R (2021) Information or habit: What health policy makers should know about the drivers of self-medication among Romanians. International Journal of Environmental Research and Public Health, 18, 689. CrossRef.

EC - European Commission (2013a) Eurobarometer 72.5 (Nov-Dec 2009). Available at: https://search.gesis.org/research'data/ZA4999

EC - European Commission (2013b) Health inequalities in the EU - Final report of a consortium. Consortium lead: Sir Michael Marmot. Available at: https://ec.europa.eu/health/sites/health/files/social_determinants/docs/healthinequalitiesineu_2013_en.pdf 
EC - European Commission (2017) Eurobarometer 79.4 (2013). Available at: https://search.gesis.org/research_data/ZA5852

EC - European Commission (2019a) Eurobarometer 85.1 (2016). Available at: https://search.gesis.org/research_data/ZA6693

EC - European Commission (2019b) Eurobarometer 90.1 (2018). Available at: https://search.gesis.org/research_data/ZA7484

ECDC - European Centre for Disease Prevention and Control (2013) Health inequalities, the financial crisis, and infectious disease in Europe. Available at: https://www.ecdc.europa.eu/sites/default/files/media/en/publications/Publications/Health_inequalities_financial_crisis.pdf

ECDC - European Centre for Disease Prevention and Control (2020) Data from the ECDC surveillance atlas - Antimicrobial resistance. Available at: https://www.ecdc.europa.eu/en/antimicrobial-resistance/surveillance-and-disease-data/data-ecdc

Eggermont D, Smit MAM, Kwestroo GA, Verheij RA, Hek K, Kunst AE (2018) The influence of gender concordance between general practitioner and patient on antibiotic prescribing for sore throat symptoms: A retrospective study. BMC Family Practice 19: 175. CrossRef.

Eurostat (2019) Gini coefficient of equivalised disposable income - EU-SILC survey. Available at: https://appsso.eurostat.ec.europa.eu/nui/show.do?.dataset=ilc_di12\&lang $=$ en

Fairbrother M (2014) Two multilevel modeling techniques for analyzing comparative longitudinal survey datasets. Political Science Research and Methods 2: 119-140. CrossRef.

Foot H, la caze A, Gujral G, Cottrell N (2016) The necessity-concerns framework predicts adherence to medication in multiple illness conditions: A meta-analysis. Patient Education and Counseling 99: 706-717. CrossRef.

Gaygisiz U, Lajunen T, Gaygisiz E (2017) Socio-economic factors, cultural values, national personality and antibiotics use: A cross-cultural study among European countries. Journal of Infection and Public Health 10: 755-760. CrossRef.

Greenstein J (2020) The precariat class structure and income inequality among US workers: 1980-2018. Review of Radical Political Economics 52: 447-469. CrossRef.

Grigoryan L, Burgerhof J, Deschepper R, Lundborg C, Monnet D, Scicluna E, Birkin J, Haaijer-Ruskamp F (2007) Attitudes, beliefs and knowledge concerning antibiotic use and self-medication: A comparative European study. Pharmacoepidemiology and Drug Safety 16: 1234-1243. CrossRef.

Grigoryan L, Haaijer-Ruskamp FM, Burgerhof JGM, Mechtler R, Deschepper R, Tambicandrasevic A, Andrajati R, Monnet DL, Cunney R, di matteo A, Edelstein H, Valinteliene R, Alkerwi A, Scicluna EA, Grzesiowski P, Bara AC, Tesar T, Cizman M, Campos J, Lundborg CS, Birkin J (2006) Self-medication with antimicrobial drugs in Europe. Emerging Infectious Diseases 12: 452-459. CrossRef.

Grigoryan L, Monnet D, Haaijer-Ruskamp FM, Bonten MJM, Lundborg S, Verheij TJM (2010) Self-medication with antibiotics in Europe: A case for action. Current Drug Safety 5: 329-332. CrossRef.

Guinovart MC, Figueras A, Llor C (2018) Selling antimicrobials without prescription: Far beyond an administrative problem. Enfermedades infecciosas y microbiologia clinica (English ed.) 36: 290-292. CrossRef.

Hay SI, Rao PC, Dolecek C, Day NPJ, Stergachis A, Lopez AD, Murray CJL (2018) Measuring and mapping the global burden of antimicrobial resistance. $B M C$ Medicine 16: 78. CrossRef. 
Hofstede G (2011) Dimensionalizing cultures: The hofstede model in context. Online Readings in Psychology and Culture 2. CrossRef.

Hofstede G (2015) Dimension data matrix. Available at: https://geerthofstede.com/research-and-vsm/dimension-data-matrix/

Horne R, Chapman SCE, Parham R, Freemantle N, Forbes A, Cooper V (2013) Understanding patients' adherence-related beliefs about medicines prescribed for long-term conditions: A meta-analytic review of the necessity-concerns framework. PLoS One 8: e80633. CrossRef.

Horvat OJ, Tomas AD, Kusturica MMP, Savkov AV, Bukumirić DU, Tomić ZS, Sabo AJ (2017) Is the level of knowledge a predictor of rational antibiotic use in Serbia? PLoS ONE 12: e0180799

Jamhour A, El-kheir A, Salameh P, Hanna PA, Mansour H (2017) Antibiotic knowledge and self-medication practices in a developing country: A cross-sectional study. American Journal of Infection Control 45: 384-388. CrossRef.

Joseph NM, Bhanupriya B, Shewade DG, Harish BN (2015) Relationship between antimicrobial consumption and the incidence of antimicrobial resistance in Escherichia coli and Klebsiella pneumoniae isolates. Journal of Clinical and Diagnostic Research 9: DC08-DC12. CrossRef.

Kardas P, Pechère JC, Hughes DA, Cornaglia G (2007) A global survey of antibiotic leftovers in the outpatient setting. International Journal of Antimicrobial Agents 30: 530-536. CrossRef.

Kim SS, Moon S, Kim EJ (2011) Public knowledge and attitudes regarding antibiotic use in South Korea. Journal of the Korean Academy of Nursing 41: 742-749. CrossRef.

Kino S, Bernabé E, Sabbah W (2017) Socioeconomic inequality in clusters of healthrelated behaviours in Europe: latent class analysis of a cross-sectional european survey. 17: 497

Klein EY, Boeckel TPV, Martinez EM, Pant S, Gandra S, Levin SA, Goossens G, Laxminarayan R (2018) Global increase and geographic convergence in antibiotic consumption between 2000 and 2015. PNAS 115: e3463-e3470

Lafaurie M, Porcher R, Donay JL, Touratier S, Molina JM (2012) Reduction of fluoroquinolone use is associated with a decrease in methicillin-resistant Staphylococcus aureus and fluouroquinolone-resistant Pseudomonas aeruginosa isolation rates: A 10 year study. Journal of Antimicrobial Chemotherapy 67: 1010-1015. CrossRef.

Lawes T, López-lozano JM, Nebot CA, Macartney G, Subbarao-Sharma R, Dare CRJ, Wares KD, Gould IM (2015) Effects of national antibiotic stewardship and infection control strategies on hospital-associated and community-associated methicillin-resistant Staphylococcus aureus infections across a region of Scotland: A non-linear time-series study. Lancet Infectious Diseases 15: 1438-1349. CrossRef.

Lepper PM, Grusa E, Reichl H, Hogel J, Trautmann M (2002) Consumption of imipenem correlates with $\beta$-lactam resistance in Pseudomonas aeruginosa. Antimicrobial Agents and Chemotherapy 46: 2920-2925. CrossRef.

Lescure D, Paget J, Schellevis F, van Dijk L (2018) Determinants of self-medication with antibiotics in European and Anglo-Saxon countries: A systematic review of the literature. Frontiers in Public Health 6: 370. CrossRef.

Lombardi F, Gaia P, Valaperta R, Cornetta M, Tejada MR, Girolamo LD, Moroni A, Ramundo F, Colombo A, Valisi M, Costa E (2015) Emergence of carbapenem-resistant Klebsiella pneumoniae: Progressive spread and four-year period of observation in a cardiac surgery division. BioMed Research International 2017: 1-7. CrossRef. 
Machowska A, Lundborg S (2019) Drivers of irrational use of antibiotics in Europe. International Journal of Environmental Research and Public Health 16: 27. CrossRef.

Mackenbach JP, Merrding WJ, Kunst AE (2011) Economic costs of health inequalities in the European union. Journal of Epidemiology and Community Health 65: 412-419. CrossRef.

McNulty CAM, Boyle P, Nichols T, Clappison P, Davey P (2006) Antimicrobial drugs in the home, United Kingdom. Emerging Infectious Diseases 12: 1523-1526. CrossRef.

McNulty CAM, Boyle P, Nichols T, Clappison P, Davey P (2007a) Don't wear me out - the public's knowledge of and attitudes to antibiotic use. Journal of Antimicrobial Chemotherapy 59: 727-738. CrossRef.

McNulty CAM, Boyle P, Nichols T, Clappison P, Davey P (2007b) The public's attitudes to and compliance with antibiotics. Journal of Antimicrobial Chemotherapy 60(Suppl. 1): i63-i68. CrossRef.

McParland JL, Williams L, Gozdzielewska L, Young M, Smith F, MacDonald J, Langdridge D, Davis M, Price L, Flowers P (2018) What are the 'active ingredients' of interventions targeting the public's engagement with antimicrobial resistance and how might they work? British Journal of Health Psychology 23: 804-819. CrossRef.

Mladenovic-Antic S, Kocic B, Velickovic-Radovanovic R, Dinic M, Petrovic J, Randjelovic G, Mitic R (2016) Correlation between antimicrobial consumption and antimicrobial resistance of Pseudomonas aeruginosa in a hospital setting: A 10-year study. Journal of Clinical Pharmacy and Therapeutics 41: 532-537

Mueller T, Östergren PO (2016) The correlation between regulatory conditions and antibiotic consumption within the WHO European region. Health Policy 120: 882-889. CrossRef.

Napolitano F, Izzo MT, Giuseppe GD, Angelillo IF (2013) Public knowledge, attitudes, and experience regarding the use of antibiotics in Italy. PLoS ONE 8: e84177. CrossRef.

Paget J, Lescure D, Versporten A, Goossens H, Schellevis F, van Dijk L (2017) Antimicrobial resistance and causes of non-prudent use of antibiotics in human medicine in the EU. April 2017. European Commission

Pan H, Cui B, Zhang D, Farrar J, Law F, Ba-Thein W (2012) Prior knowledge, older age, and higher allowance are risk factors for self-medication with antibiotics among university students in Southern China. 7: e41314. CrossRef.

Parienti JJ, Cattoir V, Thibon P, Lebouvier G, Verdon R, Daubin C, Dheyron D, Leclercq R, Charbonneau P (2011) Hospital-wide modification of fluoroquinolone policy and methicillin-resistant Staphyloccocus aureus rates: a 10-year interrupted time-series analysis. The Journal of Hospital Infection 78: 118-122. CrossRef.

Pavydė E, Veikutis V, Mačiulienė A, Mačiulis V, Petrikonis K, Stankevičius E (2015) Public knowledge, beliefs and behavior on antibiotic use and self-medication in Lithuania. International Journal of Environmental Research and Public Health 12: 7002-7016. CrossRef.

Pechère JC, Hughes D, Kardas P, Cornaglia G (2007) Non-compliance with antibiotic therapy for acute community infections: A global survey. International Journal of Antimicrobial Agents 29: 245-253. CrossRef.

Pouwels KB, Chatterjee A, Cooper BS, Robotham JV (2019) Antibiotic resistance, stewardship, and consumption. Lancet Oncology 3: e66. CrossRef. 
Price L, Gozdzielewska L, Young M, Smith F, Macdonald J, Mcparland J, Williams L, Langdridge D, Davis M, Flowers P (2018) Effectiveness of interventions to improve the public's antimicrobial resistance awareness and behaviours associated with prudent use of antimicrobials: A systematic review. Journal of Antimicrobial Chemotherapy 73: 1464-1478. CrossRef.

Pärnänen KMM, Narciso-da Rocha C, Kneis D, Berendonk TU, Cacace D, Do TT, Elpers C, Fatta-Kassinos D, Henriques I, Jaeger T, Karkman A, Martinez JL, Michael SG, Michael-Kordatou I, O'Sullivan K, Rodriguez-Mozaz S, Schwartz T, Sheng H, Sørum H, Stedtfeld RD, Tiedje JM, Giustina SVD, Walsh F, Vaz-Moreira I, Virta M, Manaia CM (2019) Antibiotic resistance in European wastewater treatment plants mirrors the pattern of clinical antibiotic resistance prevalence. Science Advances 5: eaau9124. CrossRef.

Reeves A, McKee M, Basu S, Stuckler D (2014) The political economy of austerity and healthcare: Cross-national analysis of expenditure changes in 27 European nations 1995-2011. Health Policy 115: 1-8. CrossRef.

Rönnerstrand B, Lapuente V (2017) Corruption and use of antibiotics in regions of Europe. Health Policy 121: 250-256. CrossRef.

Rossolini GM, Mantengoli E (2005) Treatment and control of severe infections caused by multiresistant Pseudomonas aeruginosa. Clinical Microbiology and Infection 11: 17-32. CrossRef.

Sargent C, Kotobi L (2017) Austerity and its implications for immigrant health in France. Social Science \& Medicine 187: 259-267. CrossRef.

Savoldi A, Carrara E, Gladstone BP, Azzini AM, Göpel S, Tacconelli E (2019) Gross national income and antibiotic resistance in invasive isolates: analysis of the top-ranked antibiotic-resistant bacteria on the 2017 WHO priority list. Journal of Antimicrobial Chemotherapy: in press. CrossRef.

Schmidt-Catran AW, Fairbrother M (2016) The random effects in multilevel models: Getting them wrong and getting them right. European Sociological Review 32: 23-38. CrossRef.

Scicluna EA, Borg MA, Gür D, Rasslan O, Taher I, Redjeb. SB, Elnassar Z, Bagatzouni DP, Daoud Z (2009) Self-medication with antibiotics in the ambulatory care setting within the euro-mediterranean region; results from the ARMed project. Journal of Infection and Public Health 2: 189-197. CrossRef.

Shabani Z, Redican KJ (2018) Antibiotic self-medication among young adults in Kosovo. International Journal of Healthcare and Medical Sciences 4: 134-140

Shehadeh M, Suaifan G, Darwish RM, Wazaify M, Zaru L, Alja'fari S (2012) Knowledge, attitudes and behavior regarding antibiotics use and misuse among adults in the community of Jordan: A pilot study. Saudi Pharmaceutical Journal 20: 125-133. CrossRef.

Skliros E, Merkouris P, Papzafiropoulou A, Gikas A, Matzouranis G, Papagragos C, Tsakanikas I, Zarbala I, Vasibosis A, Stamataki P, Sotiropoulos (2010) Self-medication with antibiotics in rural population in Greece: a cross-sectional multicenter study. BMC Family Practice 11: 58. CrossRef.

Standing G (2014) The Precariat: The New Dangerous Class. Bloomsbury Publishing, London, New Delhi, New York, Sydney. CrossRef.

Stuckler D, Reeves A, Loopstra R, Karanikolos M, Mckee M (2017) Austerity and health: the impact in the UK and Europe. European Journal of Public Health 27: 18-21. CrossRef. 
UK Government Cabinet Office (2017) National risk register of civil emergencies. Available at: https://assets.publishing.service.gov.uk/government/uploads/system/uploads/attachment_data/file/644968/UK_National_Risk_Register_2017.pdf

Vallin M, Polyzoi M, Marrone G, Rosales-klintz S, Wisell KT, Lundborg CS (2016) Knowledge and attitudes towards antibiotic use and resistance - A latent class analysis of a Swedish population-based sample. PLoS ONE 11: e0152160. CrossRef.

WHO - World Health Organisation (2017) Global priority list of antibiotic-resistant bacteria to guide research, discovery, and development of new antibiotics. Available at: https://www.who.int/medicines/publications/WHO-PPL-Short_Summary_25FebET_NM_WHO.pdf

WHO - World Health Organisation (2019) Ten threats to global health in 2019. Available at: https://www.who.int/news-room/spotlight/ten-threats-to-global-health-in-2019

World Bank (2020a) GDP per capita (current US\$). Available at: https://data.worldbank.org/indicator/NY.GDP.PCAP.CD

World Bank (2020b) Out-of-pocket expenditure per capita (current US\$). Available at: https://data.worldbank.org/indicator/SH.XPD.OOPC.PC.CD

World Bank (2020c) World governance indicators. Available at: https://info.worldbank.org/governance/wgi/

Wright EA, Fothergill JL, Paterson S, Brockhurst MA, Winstanley C (2013) Subinhibitory concentrations of some antibiotics can drive diversification of Pseudomonas aeruginosa populations in artificial sputum medium. BMC Microbiology 13: 170. CrossRef.

Wright GD (2007) The antibiotic resistome: the nexus of chemical and genetic diversity. Nature Reviews Microbiology 5: 175-186. CrossRef.

Yang P, Chen Y, Jiang S, Shen P, Lu X, Xiao Y (2020) Association between the rate of third generation cephalosporin-resistant Escherichia coli and Klebsiella pneumoniae and antibiotic consumption based on 143 chinese tertiary hospitals data in 2014. European Journal of Clinical Microbiology \& Infectious Diseases 39: 1495-1502. CrossRef.

Zhang A, Hobman EV, Barro PD, Young A, Carter DJ, Byrne M (2021) Self-medication with antibiotics for protection against COVID-19: The role of psychological distress, knowledge of, and experiences with antibiotics. 10: 232. CrossRef.

c) (7) (8) (C) 2021 by the authors. Licensee: REGION - The Journal of ERSA, European Regional Science Association, Louvain-la-Neuve, Belgium. This article is distributed under the terms and conditions of the Creative Commons Attribution, Non-Commercial (CC BY NC) license (http://creativecommons.org/licenses/by-nc/4.0/). 